\title{
Performance of Selected Tef Genotype for High Potential Areas of Ethiopia
}

\author{
Yazachew Genet*, Tsion Fikre, Worku Kebede, Solomon Chanyalew, Kidist Tolosa, Kebebew Assefa \\ Ethiopian Institutes of Agricultural Research; Debrezeit Agricultural Research Centre, Debre Zeit, Ethiopia
}

\author{
Email address: \\ yazachewgenet@gmail.com (Y. Genet) \\ ${ }^{*}$ Corresponding author
}

\section{To cite this article:}

Yazachew Genet, Tsion Fikre, Worku Kebede, Solomon Chanyalew, Kidist Tolosa, Kebebew Assefa. Performance of Selected Tef Genotype for High Potential Areas of Ethiopia. Ecology and Evolutionary Biology. Vol. 5, No. 3, 2020, pp. 35-42. doi: 10.11648/j.eeb.20200503.11

Received: July 17, 2020; Accepted: July 28, 2020; Published: August 17, 2020

\begin{abstract}
Genetic improvement of native crops is a promising strategy to combat hunger in the developing world. Tef is the major staple food crop for approximately 73 million people in Ethiopia. As an indigenous cereal, it is well adapted to diverse climatic and soil conditions; however, its productivity is extremely low mainly due to lack of high yielder genotypes, susceptibility to lodging, biotic and abiotic stresses. To circumvent these problem, an experiment comprising 20 tef genotypes including the standard and local checks were evaluated in a randomized complete block design with four replications at nine environment to develop high yielding, stable and farmers preferred variety (ies) for high potential areas. Combined analysis of variance revealed highly significant $(\mathrm{P} \leq 0.01)$ variations due to genotypes, environments for most of traits and significant $(\mathrm{p}$ $\leq 0.05$ ) genotype by environment interaction effects (GEI) for grain yield. AMMI analysis revealed $7.62 \%, 67.27 \%, 25.11 \%$ variation in grain yield due to genotypes, environments and GEI effects, respectively. The mean grain yield value of genotypes averaged over environments indicated that G12 (DZ-Cr-387 X Rosea (RIL-133) had the highest grain yield (2761 kgha ${ }^{-1}$ ) compared to the standard check variety Negus $\left(2526 \mathrm{kgha}^{-1}\right)$. In addition this candidate variety proved stable across environments for grain yield during the variety evaluation experiment. Therefore, this genotype was evaluated by the national variety released committee for release as a new variety for the year of 2019/20 and the technical committee approved it for fully released as new variety in 2020 . Thus, this variety should be used as a commercial variety for potential tef growing areas to increase tef productivity and production in the country.
\end{abstract}

Keywords: Tef, Genotypes, RIL, Multi Environment, GEI

\section{Introduction}

Background

Tef (Eragrostis tef) is being labeled as one of the latest super foods of the $21^{\text {st }}$ century, like the ancient Andean grain quinoa, tef's international popularity is rapidly growing [3] mainly because the grains are free from gluten to which many people are allergic [24] a causal agent for celiac disease; hence, tef is becoming globally popular as a life-style crop [22]. Tef is a resilient crop that performs better than other cereals under local conditions including drought, waterlogging, and poor soil. Since it produces a reasonable yield when grown in areas that experience moisture scarcity, it is considered as a low risk crop $[15,16]$. Tef is nutritious due to its high protein and mineral content $[1,9]$. Tef is one of the most significant crops for farm income, food and nutrition security in Ethiopia. It serves both as a staple and cash crop in the country.

Tef is versatility crop in adapting to adverse environmental conditions and staple food for $\sim 73$ million people in Ethiopia where it is annually cultivated by 7 million small-scale farmers on more than $30 \%$ of the total area allocated to cereal crops [4] In a country of more than 100 million people, tef accounts for about $15 \%$ of all calories consumed and, contribute well over $66 \%$ of the protein intake of the population consuming it as their staple food. The crop is preferred both by farmers and consumers because of its excellent nutritional quality (well balanced protein and minerals) and it makes good quality "injera", pancake-like soft bread. The straw serves as an indispensable feed for cattle and has almost equal value as the grain. 
Grain yield is a complex character which is dependent on a number of other characters and is highly influenced by many genetic factors as well as environmental fluctuations. On the other hand, the genotype $\mathrm{x}$ environment interaction (GEI) is an important aspect of both plant breeding program and the introduction of new crop cultivars $[8,12,20]$

Despite its importance, the productivity of tef is much lower than other cereals. The national average yield of tef is about 1.75 tha $^{-1}$, compared to maize $\left(3.2\right.$ tha $\left.^{-1}\right)$ and wheat $\left(2.4\right.$ tha $\left.^{-1}\right)$, respectively [4]. The major constraints limiting productivity and production of tef are; 1) limited availability of varieties suitable for different agro-ecologies; 2) limited use of improved varieties; 3) presence of biotic and abiotic stresses; and 4) inadequate seed and extension systems.

Tef research and development efforts in Ethiopia began in the late 1950s with the objectives of addressing the afore-mentioned constraints. Over the past 24 years, tef productivity increased by about $100 \%$, from just 0.7 tha $^{-1}$ in 1994 to 1.75 tha $^{-1}$ in 2018 . In tef improvement effort grain yield constituted the highest priority [13] Therefore, tackling some of the high priority problems mentioned above is vital to increase tef productivity in the Country. Consequently, the objective of the study was to evaluate the performances of selected tef genotypes across multi-locations and identify candidate variety (ies) having broad and /or specific adaptation to different environments.

\section{Materials and Methods}

\subsection{Plant Materials}

Eighteen promising recombinant inbred lines(RILs) selected from preliminary yield trial plus two checks (local and standard check) were used. The 18 promising recombinant inbred lines were obtained through single seed descent (SSD) method from two different crosses. In both crosses Quncho (DZ-Cr-387/RIL 355) was used as the ovule parent. The cultivars Rosea and Alba described by [17] were used as pollen parent. The former cultivar is characterized by high number of florets per spikelet and hence used to pyramid yield traits into the popular variety Quncho released in 2006 [13]. Likewise, the cultivar Alba was the paternal parent for six of the 18 RILs, and the cross of Quncho with cultivar Alba aimed at introgressing higher panicle length for yield as well as. thick and strong culm for increased lodging tolerance into the popular variety Quncho. The standard check variety was the variety Nigus released in 2017 [21] for agro-ecologies similar to the particular set of test locations and classified as high potential tef growing areas. On the other hand, the local check is a farmers' variety commonly grown around each of the respective test locations.

Table 1. Description code of the study tef genotypes.

\begin{tabular}{ll}
\hline Code & Genotypes \\
\hline G1 & DZ-Cr- 429 (RIL 125)/Negus (standard check) \\
G2 & DZ-Cr-387 X Rosea (RIL-9) \\
G3 & DZ-Cr-387X Roseau (RIL-22) \\
G4 & DZ-Cr-387X Rosea (RIL-38) \\
G5 & DZ-Cr-387X Rosea (RIL-24) \\
G6 & DZ-Cr-387X Rosea (RIL-48) \\
G7 & DZ-Cr-387X Rosea (RIL-52) \\
G8 & DZ-Cr-387X Rosea (RIL-75) \\
G9 & DZ-Cr-387X Rosea (RIL-92) \\
G10 & DZ-Cr-387Xrosea (RIL-117) \\
G11 & DZ-Cr-387 X Rosea (RIL-121) \\
G12 & DZ-Cr-387 X Rosea (RIL-133) \\
G13 & DZ-Cr-387 XAlba (RIL-347) \\
G14 & DZ-Cr-387 XAlba (RIL-226) \\
G15 & DZ-Cr-387 X Rosea (RIL-159) \\
G16 & DZ-Cr-387 XAlba (RIL- 260) \\
G17 & DZ-Cr-387 XAlba (RIL- 279) \\
G18 & DZ-Cr-387 XAlba (RIL-249) \\
G19 & DZ-Cr-387 XAlba (RIL- 216) \\
G20 & Local \\
\hline
\end{tabular}

\subsection{Experimental Locations and Seasons}

Although the experiment was done for two seasons at each of the six locations and also additional other locations, the data for some of the years and locations were excluded because of the heterogeneity of variance in the combined analyses of grain yield data over all environments (locations and seasons). The test locations represent high potential tef growing areas with optimum rainfall and other climatic and edaphic conditions suitable for tef production (Table 2).

Table 2. The nine test environments used for the national variety trial for high potential areas.

\begin{tabular}{llllllll}
\hline \multicolumn{2}{l}{ Locations } \\
\hline Code & Name latitude & latitude & longitude & Altitude (m.a.s.l) & Annual rainfall & mean Temperature & Soil type \\
\hline E1 & Akaki & $8^{\circ} 54^{\prime} \mathrm{N}$ & $38^{\circ} 45^{\prime} \mathrm{E}$ & 2205 & 1025 & 18 & vertisol \\
E2 & Minjar-1 & $8^{\circ} 45^{\prime} \mathrm{N}$ & $39^{\circ} 45^{\prime} \mathrm{E}$ & 2000 & 1118 & 19.5 & nitosol \\
E3 & Holeta-1 & $09^{\circ} 03^{\prime} \mathrm{N}$ & $38^{\circ} 30^{\prime} \mathrm{E}$ & 2400 & 1102 & 14.5 & nitosol \\
E4 & Adadi-1 & $08^{\circ} 31^{\prime} \mathrm{N}$ & $38^{\circ} 13^{\prime} \mathrm{E}$ & 2383 & 1105 & 16.5 & vertisol \\
E5 & Minjar-2 & $8^{\circ} 45^{\prime} \mathrm{N}$ & $39^{\circ} 45^{\prime} \mathrm{E}$ & 2000 & 1118 & 19.5 & nitosol \\
E6 & Holeta-2 & $09^{\circ} 03^{\prime} \mathrm{N}$ & $38^{\circ} 30^{\prime} \mathrm{E}$ & 2400 & 1102 & 14.5 & nitosols \\
E7 & Adadi-2 & $08^{\circ} 31^{\prime} \mathrm{N}$ & $38^{\circ} 13^{\prime} \mathrm{E}$ & 2383 & 1105 & 16.5 & vertisol \\
E8 & Bichena & $10^{\circ} 26^{\prime} \mathrm{N}$ & $38^{\circ} 12^{\prime} \mathrm{E}$ & 2543 & 1316 & 16.4 & vertisol \\
E9 & Adet & $11^{\circ} 16^{\prime} \mathrm{N}$ & $37^{\circ} 29^{\prime} \mathrm{E}$ & 2174 & 1209 & 16.5 & vertisol \\
\hline
\end{tabular}

*Climatic and edaphic information was obtained from their respective research and sub centers. Minjar-1=Minjar-2, Holeta-1=Holeta-2, Adadi-1=Adadi-2 are the same site, respectively. 


\subsection{Experimental Design and Management}

The field experiment was conducted using a randomized complete block design with four replications of $2 \mathrm{~m} \mathrm{x} 2 \mathrm{~m} \mathrm{(4 \textrm {m } ^ { 2 } )}$ plot size during the two main seasons of 2017 and 2018. The field experiment was managed as per the research recommendation of agronomic practices of the respective test locations.

\subsection{Data Collected}

Data on agronomic yield and yield related traits were collected both on plot and individual plant base. Data on days to heading or panicle emergence using the sowing date as a reference, lodging index, grain and biomass yield were taken on plot bases. Days of heading and maturity were taken when each plot attained 50\% heading (panicle emergency) and 90\% physiological maturity respectively, and days were calculated beginning from the date of sowing. Lodging index was assessed using the method of [2] by considering assessments of both the lodging degree or the angle of leaning on 0 (completely upright) to 5 (completely flat on the ground) and the severity as the percentage of the plot stand manifesting each of the 0-5 degrees of lodging. Then, lodging index for each plot was taken as the product sum of the degree of leaning and the respective per cent severity divided by five. Grain yield ( $g$ ) of each plot was measured on clean, sun dried seed and the measured grain yield value $(\mathrm{g})$ has converted to kilogram per hectare for data analysis.

Plant height $(\mathrm{cm})$, and panicle length $(\mathrm{cm})$ were taken on the five individual samples of plants which were randomly taken from the central rows of each plot, and the averages of five sample plants were as used for analysis.

\subsection{Data Analyses}

For each trait analysis of variance was made first for individual location, and ultimately upon getting positive results from tests of homogeneity of variances using the method F-max of [11], a combined analysis of variance was made across the environments (locations and years) in order to determine the differences between genotypes across environments, among environments and their interaction. For the analysis of variance, Proc GLM (general linear model) suitable for the experimental design were employed [10] using SAS software version 9.00 [23] and the average performance for different traits presented below (Table 3). AMMI (additive main effects, multiplicative interactions analysis was used to adjust the main or additive genotype and environmental effects by analysis of variance, in addition to the adjustment of the multiplicative effects for the $\mathrm{G} \times \mathrm{E}$ interaction by principal component analysis.

The sum of squares of the $\mathrm{G} \times \mathrm{E}$ interaction was divided into an singular axis or Interaction Principal Component Axis (IPCA), which reflects the standard portion in which each axis corresponded to a particular AMMI model. Mean comparison for traits showing significant differences in the analyses of variance were made using Least Significant Difference (LSD). GEA-R (2015) software version 2.0 was used for the stability analysis and GGE biplot analysis to visualize which genotypes performed bets in which environment.

\section{Result and Discussion}

\subsection{Components of Variation}

ANOVA from additive main effect and multiplicative interaction (AMMI) for most of traits showed significant ( $p$ $\leq 0.01)$ for genotypes and environments and significant $(\mathrm{P} \leq 0.05)$ effect for genotype by environment interaction (GEI). The effect of environment, genotypes and genotype by environment interaction accounted for $67.27 \%, 7.62 \%$ and $25.11 \%$ of the total sum squares (Table 3), respectively. A large sum of squares for environments indicated that the test environments were diverse with large differences among environmental means which causing most of the variation in grain yield. Therefore, this result designated the reliability of the multi environment experiments. The variation in temperature, rainfall, soil type, soil fertility, and moisture availability might be the main reasons for the presence of variation. The AMMI analysis also showed that the first interaction principal component (PC1) and second interaction principal component (PC2) explained $39.32 \%$ and $19.61 \%$ of the interaction sum squares, respectively. The mean squares for PC1 was highly significant $(\mathrm{p}<0.01)$. Likewise, analysis of variance revealed highly significant $(\mathrm{p}<0.01)$ effect GEI for aboveground biomass, days to heading, days to maturity, panicle length, plant height and lodging index. The significant interaction indicated that the genotypes respond differently across the different environments. The significant interaction indicated that the genotypes respond differently across different environments. The significant variability of genotypes traits showed in the present study for different traits of tef genotypes are in agreement with the previous report by different authors for genotype variability $[12,18]$.

Table 3. AMMI analysis of variance for grain yield grown at nine environments.

\begin{tabular}{|c|c|c|c|c|c|c|}
\hline Source & DF & SS & M.S. & V.r. & F pr & Explained GEI SS\% \\
\hline Treatment & 179 & 146663414 & 819349 & 4.14 & $<0.001$ & \multirow{4}{*}{$\begin{array}{l}7.62 \\
67.27\end{array}$} \\
\hline Genotypes (G) & 19 & 11182431 & 588549 & 2.97 & $<0.001$ & \\
\hline Environments (E) & 8 & 98656693 & 12332087 & 7.85 & $<0.001$ & \\
\hline Block (E) & 27 & 42427854 & 1571402 & 7.94 & $<0.001$ & \\
\hline Interaction (GEI) & 152 & 36824290 & 242265 & 1.22 & 0.05 & 25.11 \\
\hline PC1 & 26 & 14477805 & 556839 & 2.81 & $<0.001$ & 39.32 \\
\hline $\mathrm{PC} 2$ & 24 & 7222800 & 300950 & 1.52 & 0.055 & 19.61 \\
\hline
\end{tabular}

$\mathrm{DF}=$ degree of freedom, $\mathrm{S} . \mathrm{S}=$ Sum squares, $\mathrm{V} . \mathrm{r}=\mathrm{F}$ calculated value, $\mathrm{Fpr}=\mathrm{F}$ probability Value 


\subsection{Mean performance of Selected Tef Genotypes}

The mean grain yield performances of the 20 tef genotypes at each of the nine test environments are presented in Table 4. The overall mean grain yield of tef genotypes for the nine environments ranged from $1718 \mathrm{~kg} \mathrm{ha}^{-1}$ at E8 (Bichena-2018) to $3846 \mathrm{kgha}^{-1}$ at E2 (Minjar-2017). Among nine environments, E2 (Minijar-2017), E1 (Akaki), E5 (Holeta-2), E4 (Adadimariam-2017) and E3 (Holeta-2017) were high yielding environments. While, E7 (Adadimariam-2018), E8 (Bichena-2017) and E9 (Adet-2017) were low yielding environments.

On the other hand, mean grain yield value of genotypes averaged over environments ranged from $2340 \mathrm{kgha}^{-1}$ (G10) to $2761 \mathrm{kgha}^{-1}$ (G12) (Table 4). The significant GEI in the present study indicates unstable performance of the tef genotypes across the testing environments (Figure 1). Thus, it implied that the genotypes respond differently across the different environments. The test genotype G12 (DZ-Cr-387 X Rosea RIL133) was the top yielder at E5 (Holetta-2018), and the second highest yielder at E1 (Akaki-2017), E4 (Adadimariam-2017), E7 (Adadimariam-2018) and E9 (Adet-2017) (Table 4). Overall, the genotype code G12 (candidate variety), although not at all of the environments, performed better than others at least at two low yielding environments (Adadimariam-2018, and Adet-2017) and three high yielding environment (Akaki -2017), Adadimariam2017 and Minjar-2018). The huge variability in the grain yield among the 20 tef genotypes at the nine environments might be due to wide variability in climatic and soil conditions. This finding is in accordance with previous studies [7, 12, 19] that similarly reported which thereby complicates the selection and recommendations stable genotype across environment.

In genotype $\mathrm{x}$ environment interaction (GEI) the result exhibited the genotypes gave statistically higher grain yield and above ground biomass than the standard check variety. In addition to this considering the current tef and straw price, 36 Birrkg $^{-1}$ and 5 birr kg ha-1 ( $1 \mathrm{USD}=27$ birr), respectively, there was an economically meaningful difference among tested genotypes. Therefore, one promising candidate variety, DZ-Cr-387 X Rosea (RIL-133) gave grain yield (2761 $\left.\mathrm{kgha}^{-1}\right)$ and aboveground biomass $13802 \mathrm{kgha}^{-1}$ compared to the standard check variety Negus depicting grain yield $(2526.4 \mathrm{~kg} / \mathrm{ha})$ and aboveground biomass $11402 \mathrm{kgha}^{-1}$, respectively. Therefore, DZ-Cr-387 X Rosea (RIL-133) has been evaluated in by the National Variety Release Technical Committee in the variety verification trial during 2019/2020 and released as a new variety in 2020 . From the variety verification trial, the candidate variety showed promising performance than the newly released standard check variety Ebba.

The visualization of a 'which-won-where' pattern in multienvironment trials is essential to study adaptability of genotypes in the specific or across all test environments [25]. The vertex genotypes were the most responsive for being located at the greatest distance from the biplot origin. The genotypes with either the best or poorest performance in one or all environments were considered responsive [25] falling within the sectors. The GGE biplots of graph results was used to show the relative performance of all genotypes at a specific environment (Figure 1).

Table 4 Mean grain yield $\left(\mathrm{kgha}^{-1}\right)$ performance of tef genotypes across nine environments.

\begin{tabular}{|c|c|c|c|c|c|c|c|c|c|}
\hline \multirow{2}{*}{ Code } & \multicolumn{9}{|c|}{ Environments } \\
\hline & E1 & E2 & E3 & E4 & E5 & E6 & E7 & E8 & E9 \\
\hline G1 & 2980.0 & 3370 & 2544.3 & 2607.2 & 2718.8 & 2104.4 & 2116.7 & 2130.1 & 2166.3 \\
\hline G2 & 2828.8 & 3332.5 & 2479.0 & 2784.1 & 2796.9 & 2238.8 & 2529.5 & 1761.2 & 1804.8 \\
\hline G3 & 2583.8 & 3108.8 & 2605.9 & 2385.0 & 2298.1 & 2164.6 & 1753.3 & 2625.1 & 2101.9 \\
\hline G4 & 2925.0 & 3846.3 & 2436.6 & 2726.0 & 2310.6 & 2402.2 & 1895.0 & 2680.9 & 2192.0 \\
\hline G5 & 2782.6 & 3582.5 & 2901.2 & 2532.5 & 2732.5 & 2370.9 & 2080.4 & 2682.4 & 2093.6 \\
\hline G6 & 3133.8 & 3478.8 & 2830.9 & 2976.5 & 2384.4 & 2356.3 & 2158.5 & 2140.5 & 2224.9 \\
\hline G7 & 3021.3 & 3480.0 & 2488.8 & 2503.9 & 2553.8 & 1879.6 & 2059.5 & 2394.9 & 1943.9 \\
\hline G8 & 3091.3 & 3582.5 & 2367.9 & 2338.9 & 2513.1 & 2493.2 & 1926.3 & 2638.1 & 2320.3 \\
\hline G9 & 2567.5 & 3191.3 & 2591.4 & 2659.4 & 2376.3 & 1560.1 & 1718.2 & 2833.9 & 2037.4 \\
\hline G10 & 2898.8 & 3231.3 & 2157.8 & 2050.3 & 2393.1 & 2638.9 & 1792.4 & 1777.2 & 2116.1 \\
\hline G11 & 2602.5 & 3586.3 & 2549.9 & 2737.1 & 2510.0 & 2092.7 & 2435.5 & 2387.3 & 2003.4 \\
\hline G12 & 3087.5 & 3553.8 & 2640.5 & 3153.7 & 2963.8 & 2334.7 & 2512.2 & 2281.0 & 2315.9 \\
\hline G13 & 2842.5 & 3092.5 & 3113.7 & 3078.1 & 2145.0 & 2725.9 & 2326.5 & 2805.4 & 2287.3 \\
\hline G14 & 2803.8 & 3325.0 & 2923.6 & 2489.0 & 2865.6 & 2400.6 & 2244.3 & 1943.3 & 2614.7 \\
\hline G15 & 2465.0 & 3025.0 & 2678.5 & 2160.8 & 2383.1 & 2051.3 & 1735.7 & 2838.8 & 2308.3 \\
\hline G16 & 2906.3 & 3432.5 & 2726.7 & 3259.9 & 2647.5 & 2208.2 & 2076.0 & 2693.6 & 2287.3 \\
\hline G17 & 2853.8 & 3683.8 & 2741.4 & 2706.8 & 2423.1 & 2467.2 & 2343.3 & 2912.9 & 2007.6 \\
\hline G18 & 2637.8 & 2945.3 & 2628.0 & 2418.1 & 2613.8 & 2521.1 & 2105.3 & 2130.0 & 2204.1 \\
\hline G19 & 2825.0 & 3686.3 & 2654.9 & 2964.1 & 2915.0 & 2723.1 & 2190.7 & 1995.8 & 2419.8 \\
\hline G20 & 2808.8 & 3091.3 & 2801.8 & 2402.3 & 1987.5 & 2090.1 & 1881.8 & 2429.3 & 1920.0 \\
\hline $\mathrm{CV}$ & 10 & 20 & 10 & 15 & 11 & 13 & 22.9 & 29 & 10 \\
\hline LSD & 421.0 & 981.7 & 397.0 & 571.6 & 402.7 & 426.5 & 678.4 & 1020 & 320.6 \\
\hline SE & 40.8 & 78.9 & 44.3 & 54.6 & 42.4 & 49.6 & 58.0 & 94.8 & 30.6 \\
\hline
\end{tabular}

G1-G20 name of Genotypes, E1= Akaki (2017), E2= Minijar 2017, E3= Holeta (2017), E4= Adadi=2017, E5= Minijar (2018), E6= Holeta (2018), E7=Adadi (2018), E8= Bichna (2018), E9= Adet (2018), CV= coefficient of variation, LSD=leas Significant Difference and SE =Standard error. 
Table 5. Mean grain yield and other agronomic characteristics of 20 tef genotypes averaged over nine environments.

\begin{tabular}{|c|c|c|c|c|c|c|c|}
\hline Genotypes & Yldkg ha ${ }^{-1}$ & AGBkgha $^{-1}$ & PL (cm) & PH (cm) & DTH (days) & DTM (days) & LI (\%) \\
\hline G1 & $2526 \pm 116$ & 11403 & 35 & 93 & 52 & 112 & 76 \\
\hline $\mathrm{G} 2$ & $2506 \pm 103$ & 13045 & 40 & 106 & 55 & 117 & 74 \\
\hline G3 & $2403 \pm 84$ & 12104 & 41 & 106 & 58 & 115 & 74 \\
\hline G5 & $2640 \pm 110$ & 12990 & 40 & 105 & 57 & 114 & 76 \\
\hline G6 & $2632 \pm 115$ & 12514 & 38 & 101 & 55 & 113 & 76 \\
\hline G7 & $2481 \pm 99$ & 12601 & 40 & 106 & 56 & 114 & 76 \\
\hline G9 & $2393 \pm 109$ & 13288 & 42 & 105 & 59 & 113 & 74 \\
\hline G10 & $2340 \pm 100$ & 12618 & 41 & 109 & 54 & 114 & 72 \\
\hline G11 & $2545 \pm 103$ & 11910 & 41 & 104 & 55 & 114 & 78 \\
\hline G12 & $2761 \pm 95$ & 13802 & 40 & 106 & 55 & 115 & 75 \\
\hline G13 & $2713.0 \pm 106$ & 13007 & 41 & 106 & 54 & 115 & 75 \\
\hline G14 & $2623 \pm 106$ & 13250 & 40 & 105 & 57 & 116 & 73 \\
\hline G15 & $2405 \pm 93$ & 12750 & 41 & 105 & 59 & 115 & 74 \\
\hline G16 & $2686 \pm 93$ & 13347 & 42 & 112 & 56 & 114 & 74 \\
\hline G18 & $2467 \pm 124$ & 13073 & 43 & 111 & 55 & 115 & 74 \\
\hline G19 & $2708 \pm 112$ & 11014 & 33 & 90 & 51 & 111 & 80 \\
\hline $\mathrm{G} 20$ & $2379 \pm 94$ & 10837 & 36 & 95 & 52 & 114 & 80 \\
\hline Genotype (G) & $* *$ & $* *$ & $* *$ & $* *$ & $* *$ & $* *$ & $* *$ \\
\hline Environment (E) & $* *$ & $* *$ & $* *$ & $* *$ & $* *$ & $* *$ & $* *$ \\
\hline GEI & $*$ & $* *$ & $* *$ & $* *$ & $* *$ & $* *$ & $* *$ \\
\hline $\mathrm{CV}$ & 20 & 18 & 11 & 5 & 4 & 2 & 10 \\
\hline $\operatorname{LSD}(0.05)$ & 423 & 1936 & 4 & 5 & 2 & 2 & 7 \\
\hline $\mathrm{R}^{2}$ & 53 & 88 & 73 & 84 & 94 & 98 & 68 \\
\hline
\end{tabular}

Yldkgha-1 = yield kilogram per hectare, DTH= Days to heading, DTM= days to maturity, $\mathrm{PH}=$ plant height, $\mathrm{GFP}=$ grain filling period, $\mathrm{PH}=\mathrm{plant}$ height, $\mathrm{PL}=$ Panicle length, $\mathrm{LI}=$ lodging index, $\mathrm{R}^{2}(\%)=$ the model explain the variability of the response data around its mean

\subsection{Stability Analysis}

Mean grain yield performance and its stability 20 tef genotypes over nine environments are shown in table 6 and Figure 2. From GGE biplot graph for stability analysis Average environmental axis (AEA) is a line passing through the origin and pointing to the positive direction with its distance equal to the longest vector. Besides, an ideal environment is a point on the AEA in the positive direction of the biplot origin and is equal to the longest vector of all environments [25]. This line was reported to be useful to evaluate mean grain yield and stability of genotypes [25]. According to such reports, genotypes considered to be stable are those appeared closer to the origin with the shortest vector from the AEC. Thus, Figure
2 in the present study shows the mean performance and stability of the genotypes. Based on this, G12 with the shortest vector from the AEC axis was identified as the most stable genotypes while G10 with the longest vector from AEC was the most unstable genotypes.

The mean grain yield value of genotypes averaged over environments indicated that G12 had the highest $\left(2761 \mathrm{~kg} \mathrm{ha}^{-1}\right)$ and G10 the lowest grain yield $\left(2340 \mathrm{~kg} \mathrm{ha}^{-1}\right)$, respectively. Genotype superiority with the small measured value indicates the more stable genotypes (Table 6). Therefore, from the present study, G12 was the most stable and G10 most unstable genotypes, respectively.

Table 6. Stability coefficient analysis of mean grain yield of 20 tef genotypes tested across nine environments.

\begin{tabular}{llll}
\hline Genotypes & Grain yield Mean kgha $^{-1}$ & Standard Deviation $^{-1}$ & Genotype Superiority \\
\hline G1 & 2526 & 446 & $135078(12)$ \\
G2 & 2506 & 508 & $179646(15)$ \\
G3 & 2401 & 388 & $198671(16)$ \\
G4 & 2602 & 558 & $108536(8)$ \\
G5 & 2640 & 459 & $81837(5)$ \\
G6 & 2632 & 487 & $91877(7)$ \\
G7 & 2481 & 516 & $162910(13)$ \\
G8 & 2586 & 485 & $125513(11)$ \\
G9 & 2393 & 530 & $226952(19)$ \\
G10 & 2340 & 498 & $290293(20)$ \\
G11 & 2545 & 456 & $122601(10)$ \\
G12 & 2761 & 449 & $53531(1)$ \\
G13 & 2713 & 3734 & $84241(6)$ \\
G14 & 2623 & 410 & $119332(9)$ \\
G15 & 2405 & 402 & $224489(18)$ \\
G16 & 2686 & 468 & $63719(2)$ \\
\hline
\end{tabular}




\begin{tabular}{llll}
\hline Genotypes & Grain yield Mean kgha $^{-1}$ & Standard Deviation & Genotype Superiority \\
\hline G17 & 2682 & 471 & $72877(3)$ \\
G18 & 2467 & 279 & $173804(14)$ \\
G19 & 2708 & 492 & $78627(4)$ \\
G20 & 2379 & 443 & $222293(17)$ \\
\hline
\end{tabular}

N. B: Numbers in brackets give the position of each genotype, ranked according to the stability coefficient (running downwards from $1=$ best).

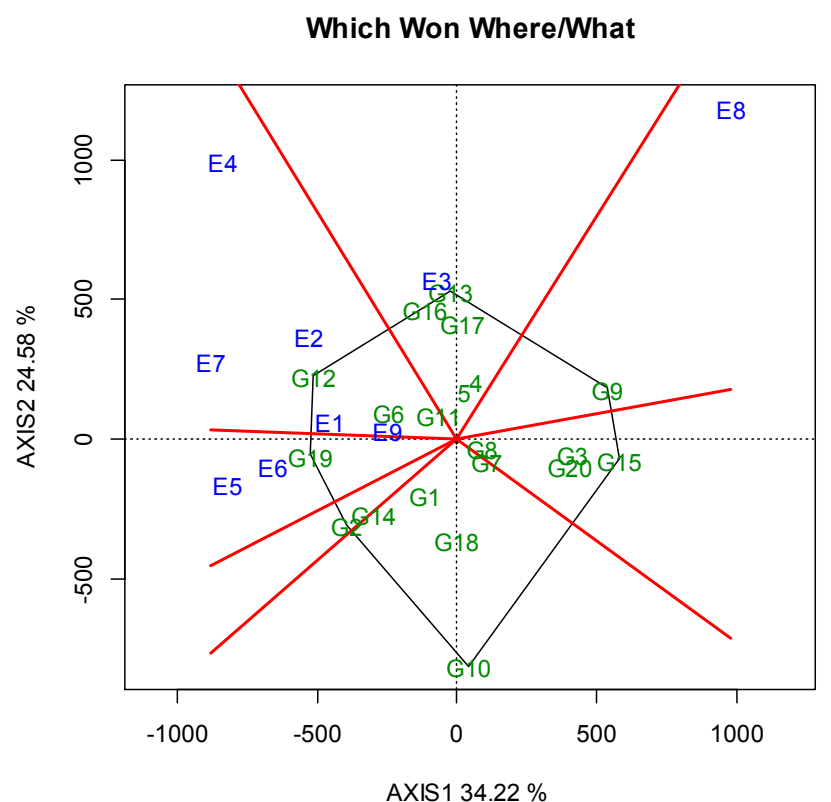

Figure 1. The which-won-where view of the GGE biplot of 20 tef genotypes to show which genotypes performed bets in which environments.

Beneficial advantage of new variety DZ-Cr.497/DZ-Cr387 X Rosea (RIL-133)

The New variety DZ-Cr.497/DZ-Cr-387 X Rosea (RIL$133) /$ has got the following major advantages.

1) It showed advantage of $235 \mathrm{kgha}^{-1}(9.3 \%)$ in grain yield and 2399 kgha-1 (21\%) in aboveground biomass yield over the standard check variety Negus as well as $16.1 \%$ in grain yield and $36.8 \%$ in aboveground biomass over the local check cultivar.

2) Moreover, the selected genotype showed highly stability (1st rank) among evaluated genotypes, indicating its suitability for multi environment in the high potential tef growing areas.

3) This genotype has also got immense farmers' preference and attention due to its overall performance and white caryopsis colour during the participatory variety evaluation.

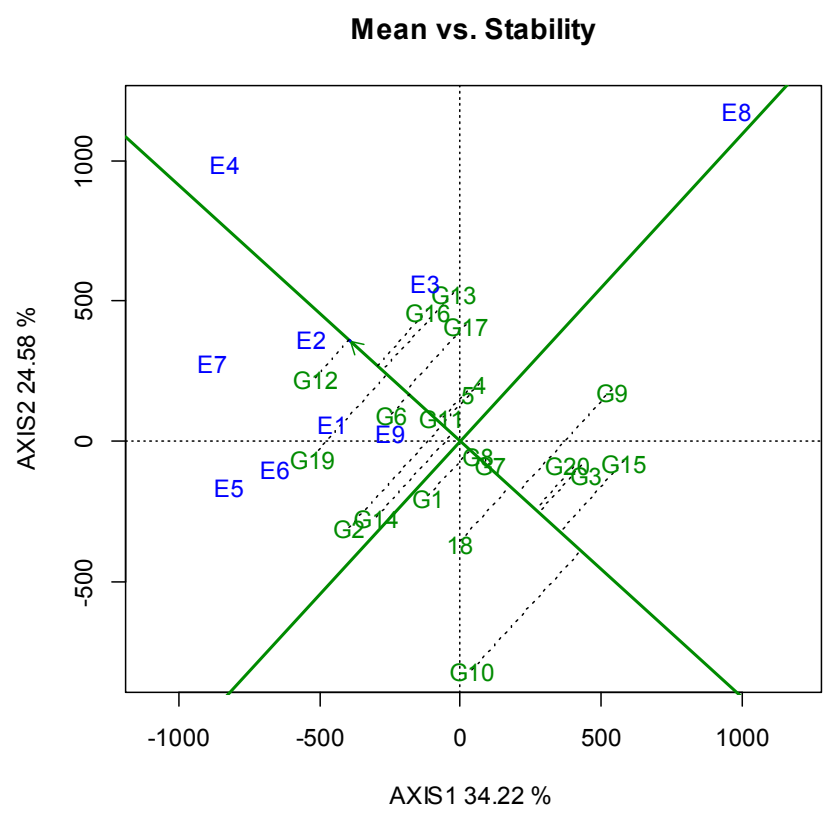

Figure 2. Means versus stability of 20 tef genotypes tested at nine environments

Description of the new variety DZ-Cr-497/ DZ-Cr-387 X Rosea (RIL-133)

A summary of the description of the candidate variety including its pedigree, adaptation agro-ecological conditions, required cultural practices, and pheno-morphologic and agronomic traits is presented on Table 7.

Table 7. Description of agronomic and morphological characteristics of the new variety DZ-Cr-387 x Rosea (RIL-133).

\begin{tabular}{lll}
\hline No. & Parameters & Description \\
\hline I & Variety Name & DZ-.Cr-497 \\
1 & Breeders Name & DZ-Cr-387 X Rosea (RIL-133) \\
2 & Pedigree & Dinknesh \\
3 & Vernacular name given & High \& optimum tef growing areas \\
II & Adaptation conditions and agronomic practice & $1700-2500$ \\
4 & Adaptation area & $700-1200$ \\
5 & Altitude (m.a.s.1.) & Mainly vertisols and nitosols \\
6 & Rain fall (mm) & $10-15$ \\
7 & Soil type & both broad casting \& row sowing \\
8 & Seed rate (Kgha $\left.{ }^{-1}\right)$ & 20 \\
9 & Planting method & July 10-30 \\
10 & Row spacing (cm) & \\
\hline
\end{tabular}




\begin{tabular}{lll}
\hline No. & Parameters & Description \\
\hline 12 & Fertilizer Use & recommended rate for tef \\
13 & Pest reaction & Not significant \\
III & Qualitative traits & \\
14 & Panicle form & Very loss \\
15 & Lemma color & Variegated (yellow+red) \\
16 & Anther color & Red \\
17 & Caryopsis color & Very white \\
18 & Growth habit & Erect \\
IV & Quantitative traits & Mean \\
19 & Days to heading (days) & 52 \\
20 & Days to maturity (days) & 112 \\
21 & Plant height (cm) & 93 \\
22 & Panicle length (cm) & 35 \\
23 & 1000 seed weight (g) & 0.3 \\
24 & Grain yield on station (kgha-1) & 2761 \\
25. & Grain yield on farm (kgha-1) & 2140 \\
26 & Aboveground biomass (kgha-1) & 13802 \\
\hline
\end{tabular}

\section{Conclusions and Recommendations}

Crop yield is a complex trait that is influenced by a number of component characters along with the environment directly or indirectly. If high yielding stable recombinant inbred lines tef could be developed for diverse environments, it would be possible to provide diverse and stable varieties for the tef growing farmers. Stability analysis is a powerful approach to select the most stable high yielding recombinant inbreeds lines for specific as well as for diverse environments. In the present study, 20 tef genotypes including 18 promising RILs originating from two crosses and selected on the basis of previous preliminary variety trials as well as as standard check variety Negus and a local check (farmers' variety) from each location were field evaluated at nine environments (six location and two main seasons of 2017 and 2018). Combined analysis of variance revealed highly significant $(\mathrm{P} \leq 0.01)$ variations due to genotypes, environments for most of traits and significant $(\mathrm{p}$ $\leq 0.05$ ) genotype by environment interaction effects (GEI) for grain yield. AMMI analysis revealed 7.62\%, 67.27\%, 25.11\% variation in grain yield due to genotypes, environments and GEI effects, respectively. Thus, the GEI mean squares showed tef genotypes exhibited differential performances across the different environments. Consequently, most of the genotypes showed environment specificity. The mean grain yield value of genotypes averaged over environments indicated that G12 had the highest (2761 kgha-1) and G10 the lowest yield $\left(2340 \mathrm{kgha}^{-1}\right)$, respectively. It is noted that the variety G12 showed higher grain yield than all other varieties when averaged over all the environments.

One promising late set candidate variety, DZ-Cr-387 X Rosea (RIL-133) gave higher grain yield of $\left(2761 \mathrm{kgha}^{-1}\right)$ compared to the standard check variety Negus (2526.4kgha $\left.{ }^{1}\right)$. Therefore, DZ-Cr-387 X Rosea (RIL-133) has been selected and evaluated by the National Variety Release Committee in 2019/2020 and released in 2020. Thus, it is recommended for high potential tef growing regions in the country. Multi environmental trial should be conducted continuously to get high yielding tef varieties for different tef growing areas to increase production and productivity of tef.

Overall, the tef varieties released have shown steady and incremental genetic gain through tef breeding in Ethiopia of $0.90 \%$ year under lodging controlled (wire-mesh support) conditions from the earliest release in 1970 until 1995 [26, 27], and $0.58 \%$ per annum under lodging uncontrolled natural conditions from 1970 until 2013 [5, 6]. These figures are relatively good by the standards of most breeding programs for similar crops, except for the most important world crops like maize, wheat and rice. However, to bring breakthrough, instead of the steady increment, in in tef improvement further intensified crossing/hybridization in order to stack productivity traits/genes, break the apparent linkage between culm thickness and culm length for reduced lodging vulnerability, and use advanced breeding techniques including genomics are vital so as to get substantially high yielder and stable genotypes with the required qualities. Moreover, future research strategies on tef genetic engineering, high throughput mutant line development, and mining of the tef genetic resources including the wild relative species must be given due emphasis in the national tef breeding program.

\section{Acknowledgements}

The authors are indebted to the Agricultural Growth Program (AGP-II) for financial support and all collaborating centres and their respective tef research staff for the successful execution of the field experiment.

\section{References}

[1] Abebe Y, Bogale A, Hambidgeb K. Michael S, Barbara J., Baileyd K \& Gibson, R. S. (2007). Phytate, zinc, iron and calcium content of selected raw and prepared foods consumed in rural Sidama, Southern Ethiopia, and implications for bioavailability. Journal of Food Composition and Analysis 20, 3-4, 161-168.

[2] Caldicott, J. J. B. and A. M. Nuttall. 1979. A method for the assessment of lodging in cereal crops. Jour. of Nat. Inst. Agri. Botany. 15: 88-91. 
[3] Collyns Dan., (2013). Quinoa brings riches to the Andes. Retrieved from http://www.theguardian.com/world/2013/jan/14/quinoa-andesbolivia-peru-crop

[4] CSA. 2018. Central Statistical Agency, Agricultural Sample Survey 2017/2018 (2010 E.C). Volume I. Report on Area and Production of Major Crops (Private Peasant Holdings, Meher Season). Statistical bulletin, 586, Addis Ababa, Ethiopia.

[5] Fano Dargo (2013). Genetic Gain in Grain Yield Grain Yield Potential and Associated Traits of Tef [Eragrostis tef (Zucc.) Trotter] in Ethiopia, MSc. Thesis, Haramaya University, Haramaya, Ethiopia.

[6] Fano Dargo, Firew Mekbib. and Kebebew Assefa (2016). Genetic Gain in Grain Yield Potential and Associated Traits of Tef [Eragrostis tef (Zucc.) Trotter] in Ethiopia. Global Journals Inc. (USA) 16: 2249-4626.

[7] Fufa Hundera, Hailu Tefera, Kebebew Assefa, Tesfaye Tefera, Tiruneh Kefyalew Girma Taye (2000). Grain yield and stability analysis in late maturing genotypes of tef [Eragrostis tef (Zucc.) Trotter]. J. Genet. Breed. 54: 13-18.

[8] Freeman GH (1985) the analysis and interpretation of interaction. Journal of Applied Statistics. 12: 3-10.

[9] Geremew Bultosa, Hall A., \& Taylor J. (2002). The World Factbook. Africa: Ethiopia. Retrieved from CIA website; https://www.cia.gov/library/publications/the-worldfactbook/geos/et.html

[10] Gomez, K. A., and A. A. Gomez. (1984). Statistical Procedures for Agricultural Research. 2nd ed., John Wiley and Sons, Inc., New York, USA.

[11] Hartley, H. O. (1950). The maximum F-ratio as a short cut test for heterogeneity of variances. Biometrika 37: 308-312.

[12] Habte Jifar, Kebebew Assefa, Kassahun Tesfaye, and Zerihun Tadele. (2019) genotype $\mathrm{x}$ environment interaction and stability analysis in grain yield of tef (Eragrostis tef) evaluated in Ethiopia. JEAI, 35 (5): 1-13; Article no. JEAI. 48459. DOI: 10.9734/JEAI/2019/v35i530214.

[13] Kebebew Assefa, Yu J, K., Zeid, M., Getachew Belay, Hailu Tefera and Sorrells, M. E. (2011).

[14] Breeding tef [Eragrostis tef (Zucc.) Trotter]: conventional and molecular approaches. Plant Breed. 130: 1-9.

[15] Seyfu Ketema. (1997). Tef. Eragrostis tef (Zucc.) Trotter. Promoting the conservation and use of underutilized and neglected crops. 12. Institute of plant genetics and crop plant Research, Gatersleben/International Plant Genetic Resources Institute, Rome, Italy.
[16] Seyfu Ketema. 1993. Tef (Eragrostis tef): Breeding, Genetic Resources, Agronomy, Utilization and Role in Ethiopian Agriculture. Institute of Agricultural Research, Addis Ababa, Ethiopia.

[17] Tadesse Ebba (1975). Tef (Eragrostis tef) Cultivars, Morphology and Classification, Part II. Experiment Station Bulletin No. 66, Addis Ababa University, College of Agriculture. Dire Dawa, Ethiopia.

[18] Tiruneh Kefyalew. Genotype x environment interaction in tef. (2001) Tefera H, Belay G, Sorrells M, (Eds). Narrowing the Rift: Tef Research and Development. Proceedings of the International Workshop on Tef Genetics and Improvement, Debre Zeit: EARO; 2001.

[19] Tiruneh Kefyalew (1999). Assessment of Genotype $x$ Environment Interaction for Yield and Yield Related Traits in Tef [Eragrostis tef (Zucc.) Trotter] Genotypes, MSc. Thesis, Alemaya University of Agriculture, Alemaya, Ethiopia.

[20] McLaren CG, Chaudhary C, (1994) Use of additive main effects and multiplicative interaction models to analyse multiplication rice variety trials. Paper presented at the FCSSP Conference, Puerton Princesa, and Palawan, Philippines.

[21] MoALR (2017). Ministry of Agriculture and Livestock Resource, Plant Variety Release, Protection and Seed Quality Control Directorate, Crop Variety Register Issue Mo. 20, Addis Ababa, Ethiopia.

[22] Provost C. and Jobson E. 2014. Move over quinoa, Ethiopia's Teff poised to be next big super grain. The Guardian, January 23, 2014.

[23] SAS Institute. (2002). SAS/STAT Guide for Personal Computers, Version 9.00 editions. Cary, N. C., SAS Institute Inc.

[24] Spaenij-Dekking L., Kooy-Winkelaar Y., Koning F. 2005, 'The Ethiopian cereal Tef in celiac disease', New England Journal of Medicine 353 (16), 1748-1750.

[25] Yan W, Tinker NA. Biplot analysis of multi- environment trial data: Principles and applications. Can J Plant Sci. 2006; 86: 623-645.

[26] Yifru Teklu (1996). Genetic Gain in Grain Yield Potential and Associated Agronomic Traits of tef [Eragrostis tef (Zucc.) Trotter], MSc. Thesis, Alemaya University of Agriculture, Dire Dawa, Ethiopia.

[27] Yifru Teklu and Hailu Tefera (2005). Genetic improvement in grain yield potential and associated agronomic traits of tef (Eragrostis tef). Euphytica 141: 247-254. 